\title{
«L'Antropologie» y el «Institut de Paleontologie Humaine»
}

\author{
E. Ripoll Perello
}

L'Anthropologie y el "Institut de Paléontologie Humaine» (I.P.H.) cumplieron hace poco su primer centenario (1890) y sus primeros ochenta años (1910) de existencia respectivamente. Tales efemérides habrían tenido que ser celebradas festivamente, pero nuestros colegas parisinos pensaron que era más adecuado el estilo escueto que ha sido siempre el de la revista y el austero del I.P.H., o sea, en ambos casos, el respeto a la memoria histórica. Es en este mismo sentido que deseamos dejar aquí plasmado el homenaje que tales conmemoraciones merecen.

Cien años de una publicación periódica especializada constituyen un importante acontecimiento científico. $Y$ aún más cuando se piensa en lo efímero de tantas revistas como se ven nacer y morir en el transcurso de unos pocos años. Teniendo en cuenta que la Prehistoria tiene poco más de 150 años de existencia como ciencia establecida, se puede decir que L'Anthropologie ha cubierto dos tercios de este tiempo, y si, por la continuidad entre ambas publicaciones, se suman los años en que aparecieron los Matériaux pour l'histoire primitive et naturelle de l'Homme (1865-1889), la cobertura de los avances científicos durante dicho período es casi total. Si no nos equivocamos, para la Prehistoria el caso de L'Antrhopologie sólo puede parangonarse con el del Bulletino di Paletnologia Italiana, fundado en $1876{ }^{1}$.

Por su parte, el I.P.H. ha cumplido sus primeros ochenta y seis años. El palacio de la esquina del Boulevard Saint-Marcel y la rue René Panhard

1 Lo crearon luigi Pigorini, Gaetano Chierici y Pellegrino Strobel. Ese mismo año 1876 es el de la creación del "Museo Preistórico Etnográfico" de Roma, que actualmente lleva, además, el nombre de Pigorini, institución de la que el Bulletino ha sido siempre el órgano escrito. Por contener muchos trabajos de Prehistoria, en particular en sus primeros tiempos, hay que subrayar aquí asimismo los más de 150 años de la Revue Archéologique, pubicación benemérita cuya historia debería escribirse. 
ha sido la casa en la que centenares de prehistoriadores de todo el mundo han adquirido o han perfeccionado su formación. Después de algún periodo de vida languidecente debido a las crisis económicas europeas, ahora es la eficiente colmena de trabajo que deseaba que fuera su fundador, el príncipe Alberto I de Mónaco.

\section{ANTECEDENTES}

L'Anthropologie tuvo un inmediato y directo precedente en los Matériaux, por lo que es conveniente recordar la historia de esta publicación periódica que es, en gran parte, la de ciencia prehistórica en su fase inicial.

El ambiente en que se movian los investigadores de la época fundacional, todos ellos amateurs (excepto Edouard Lartet -1801-1871-, que fue el primero que se profesionalizó ${ }^{2}$, era de gran apasionamiento, pero no existia ningún órgano de relación entre ellos. En el mejor de los casos se efectuaban intercambios epistolares, se visitaban los yacimientos que cada uno excavaba o "explotaba", la gente se veia en los congresos que pronto se organizaron y casi únicamente estos daban ocasión para publicar. Dicha falta de comunicación daba lugar a descubrimientos simultáneos. la discusión de problemas que ya habian encontrado solución, interpretaciones temerarias, etc. Para salvar tal vacio, el año 1865 vió nacer el primer órgano periódico de la nueva ciencia. Se llamaba Matériaux pour I'histoire positive et philosophique de l'Homme. Su fundador era Gabriel de Mortillet (1821-1898 ${ }^{3}$. La nueva publicación iba a durar veinticinco años.

Seguramente no estará de más subrayar aquí que la ciencia prehistórica había nacido "oficialmente" sólo dieciocho años antes con las Antiquités céltiques et andediluviennes de J. de $\mathrm{C}$. Boucher de Perthes (1788-1868) 4; que sólo seis años antes de la aparición de los Matériaux, Charles R. Darwin (1809-1882) había publicado su revolucionaria obra On the origin of species by means of natural selection (1859); que ese mismo año 1859, A. Gaudry presentó a la “Académie des Sciences» su memoria titulada La contemporaneité de l'espèce humaine et des diverses spèces

EUOUARD LARIFT Y HFNRI CHRISIY, Reliquiae Aquitanicae, being contributions to the archeology and paleontology of Perigord. Londres. Bailtire, 1865-1875

Gabrifl de Morthil. T. Le Préhistorique, origines et antiquite de l'homme. Paris. 1883 É. Cartallhac. "Gabriel de Mortillet", L'Anthropologie. IX, 1898, págs. 601-612, con bibliografia.

A. LAMING-EMPERARE. Origines de l'Archeologie préhistorique en France. Paris, Picard. 1964. en especial pp. 155-175, con bibliografia. 
animales aujourd'hui etéintes; que, en 1863, Charles Lyell (1797-1875) dió a conocer su difundido libro The Geological Evidences of the Antiquity of Man with remarks on theories of the origin of species by variation; y que, ese mismo año 1865, Johan Lubbock (1834-1913) publicó su Prehistoric Times, cuyas ediciones y traducciones se multiplicaron en años sucesivos. En el libro de Lubbock se utilizan por primera vez las denominaciones Paleolítico y Neolítico para subdividir la entonces Ilamada Edad de la Piedra. Pero tampoco hay que olvidar que, el año 1860, la "Académie des Sciences" habia rechazado la memoria presentada por Edouard Lartet con el título Sur l'ancienneté géologique de l'espèce humaine dans l'Europe occidentale, si bien mereció inmediatamente los honores de la letra impresa en Londres y en Ginebra ${ }^{5}$.

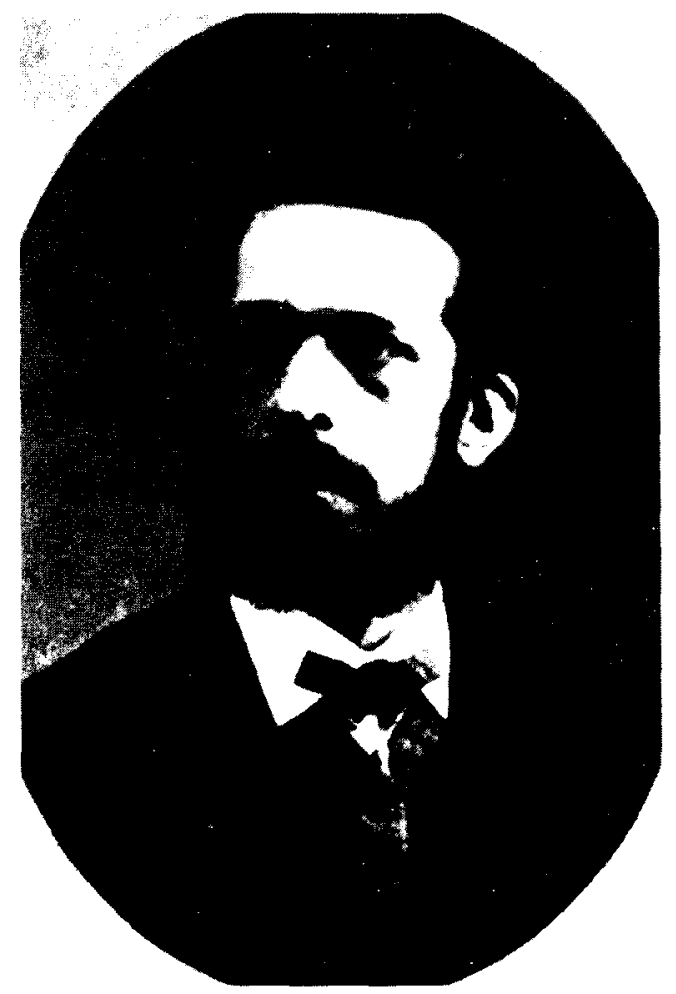

Figura 1. Émile Cartailhac (1845-1921)

E. Ripoll Pfrello, "El centenario de la Prehistoria», Ampurias, XXVI-XXVII, 1964-1965, pp. 333-338. 
En aquellos años de sus orígenes, la Prehistoria marcaba sus diferencias con la Historia propiamente dicha, al encontrarse, por sus métodos, más cerca de las Ciencias Naturales. Pero, para la historia de las ideas y de las mentalidades, acaso también conviene tener presente que en 1856 se inició la publicación de la alemana Historische Zeitschrift y que hasta 1876 no fue fundada la francesa La Revue historique, por obra de G. Monod y G. Fagniez.

Cuatro años después de su fundación, en 1869, los Matériaux fueron vendidos por $\mathrm{G}$. de Mortillet a Emile Cartailhac (1845-1921) ${ }^{6}$. Marcellin Boule lo narró así:

«En 1869, G. de Mortillet le cedió sus Matériaux por la cantidad de 2.000 francos que se vió obligado a pedir prestada a uno de sus buenos compañeros de la "École de Droit». El primer cuidado del nuevo propietario fue modificar el título de la revista..."?

En efecto, Cartailhac, que en aquella fecha sólo tenía 24 años, modificó el título de la publicación en su segunda serie, o sea a partir de 1869, que quedó así: Matériaux pour l'histoire primitive et naturelle de l'Homme (y como subtítulo: et de l'étude du sol, de la faune et de la flore qui s'y rattachent, que perdió en 1873) ${ }^{8}$. Los cambios en la cabecera reflejan las inquietudes y titubeos doctrinales y metodológicos de las primeras generaciones de prehistoriadores. Hasta 1873, Cartailhac tuvo como codirector a Émile Trutat; hasta 1883 dirigió la revista él sólo; entre 1884 y 1888, E. Chantre fue su codirector. Los Matériaux se vieron ilustrados con los nombres señeros de Brouillet, Trémeau de Rochebrune, Vibraye, Bourgedis, Delanauy, Fermond, Massénat y muchos otros.

\section{LA NUEVA REVISTA}

Con la conciencia de que se vivía un momento científico trascendental, al iniciarse el último decenio del siglo XIX y ante la inminente llegada del XX, se

6 Cartailhac fue autor de una serie importante de obras y gran número de articulos. Negó la autenticidad del arte de Altamira, pero luego se retractó y escribió con el abate Henri Breuil la primera gran monografia de la cueva de Santillana del Mar (1906). De sus Monuments primitifs des iles Baléares, Toulose, Privat, 1892 , se ha hecho recientemente una edición facsimil con texto traducido al castellano e introducción de G. Rosselló-Bordoy, Palma de Mallorca, Olañeta, 1991.

7 MARCELlin Boule, "Émile Cartailhac (1845-1921)", L'Anthropologie, XXXI, 1921, pp. $587-$ 608.

8 En 1868, Mortillet ya había modificado el nombre: Matériaux pour l'histoire primitive et philosophique de l'Homme. 


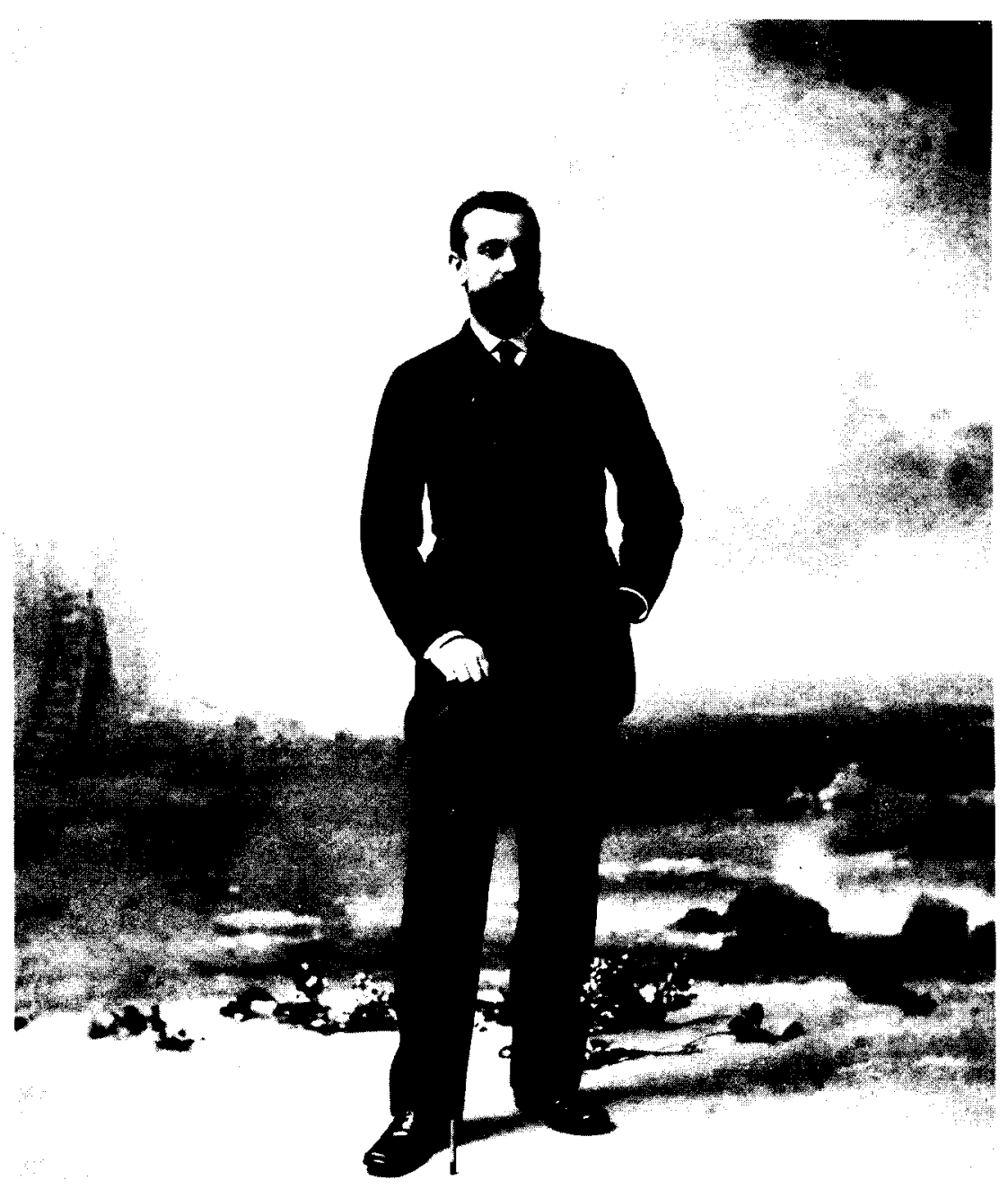

Figura 1. El Principe Alberto I de Mónaco (1948-1922)

(foto Detaille, cortesia del Musée d'Anthropologie Préhistorique de Mónaco). 
hacían nuevos planteamientos metodológicos por una parte y se evidenciaba la necesidad de coordinar la investigación de la Prehistoria con las ciencias afines, en particular la Antropología y la Etnografía. Por ello, L'Anthropologie nació de la fusión de tres prestigiosas revistas: los Matériaux, de la que hemos venido hablando, la Revue d'Anthropologie y la Revue d'Etnographie.

La Revue d'Anthropologie había sido fundada en 1871 por Paul Broca que la dirigio hasta 1880; de 1881 a 1889, su director fue Paul Topinard. Ernest T. Hamy (1842-1908), director del “Musée d'Ethnographie» del Trocadero, fue el creador de la Revue d'Ethnographie que dirigió de 1882 a $1889^{9}$.

El núcleo fundacional de promotores de la nueva publicación estaba formado por las siguientes personalidades: É. Cartailhac, P. Topinard, E.T. Hamy, Georges Masson, el príncipe Alberto I de Mónaco, Salomon Reinach, el príncipe Roland Bonaparte y Marcellin Boule. Gracias a ellos, L'Anthropologie nacía con una amplia ambición de modernidad en correspondencia con los adelantos de la ciencia prehistórica finisecular.

El primer equipo de redactores lo formaron É. Cartailhac, E.T. Hamy y Paul Topinard. En 1894 fueron sustituidos por M. Boule y Robert Verneau que siguieron en ejercicio hasta 1930. Entre los años 1931 y 1966 fueron redactores Henri V. Vallois (1989-1991) y Raymond Vaufrey (1890-1967); de 1967 a 1970, H.V. Vallois y Lionel Balout (1907-1992); y de 1971 a 1982, L. Balout y Marie-Claude Chamla. A partir de la última fecha citada se hizo cargo de la direccion Henry de Lumley, que sigue en la actualidad y que, como se dirá, ha dado un nuevo aire a la revista. Cuando se escriben estas lineas, L'Anthropologie ha llegado al tomo 99 (1995) de sus voluminosas anualidades y sigue siendo editada por la prestigiosa casa editorial Masson et Cie., con sede en el $n^{\circ} 120$ del parisino Boulevard Saint-Germain, mientras que la redacción sigue teniendo su sede en el I.P.H., del que hablaremos en esta misma nota.

Desde sus primeros tiempos, L'Anthropologie incluía en cada uno de sus fascículos los siguientes apartados: $1^{\circ}$, artículos originales sobre Antropología física, Etnografía, Paleontología humana y Arqueología prehistórica; $2^{\circ}$, con el título de "Mouvement scientifique», abundantes recensiones de trabajos producidos en Francia o fuera de ella; $3^{\circ}$, actas e informes de sociedades científicas y congresos; y $4^{\circ}$, noticias y corres-

9 En el mismo momento aparecía la Revue de l'École d'Anthropologie de Paris que no rebasó la fatídica fecha de 1914. En su redacción, entre otros, figuraban Louis Capitan y Adrien de Mortillet. En alguna ocasión hemos visto que se confundia esta revista con L'Anthropologie. Lo mismo ocurre con la checa Anthropologie, de Brno. 
pondencia. En esta última se publicaban notas biográficas con motivo del fallecimiento de distinguidos especialistas y en ocasiones con el añadido de importantes bibliografías ${ }^{10}$.

\section{LOS CONTENIDOS}

Como lo habían sido los Matériaux en su momento, L'Anthropologie se convirtió en la principal revista de Prehistoria, órgano de relación entre sus investigadores en todo el mundo, noticiario agil y vivaz de cuanto acontecía en el campo de la búsqueda de nuevos datos sobre el hombre primitivo. Particular importancia tenía la mencionada sección de recensiones bibliográficas, en la que se resumían, elogiaban o criticaban -alguna vez con dureza - multitud de trabajos de las más diversas procedencias. Desde sus primeros años, L'Anthropologie es una revista "moderna" en comparación con otras publicaciones periódicas contemporáneas, principalmente por su contenido, pero también por su presentación tipográfica y la alta calidad del papel y de la ilustración.

A continuación daremos unos pocos ejemplos de aquellos novedosos contenidos y de la seriedad con que eran tratados.

Las primeras noticias del hallazgo de Pithecanthropus erectus por E. Dubois (Batavia, 1894) enseguida encontraron un amplio eco en las páginas de la revistal ${ }^{10 \text { bis. }}$

En 1914 y 1915, M. Boule da cuenta de los primeros descubrimientos de Oldoway, entonces en el Africa Oriental alemana. Entre el descubrimiento y su noticia en las páginas de la revista apenas había transcurrido un año. Ya entonces se planteaban los problemas que todavía suscita la interpretación geológica del yacimiento ${ }^{11}$.

En 1925, a los pocos meses del sensacional descubrimiento de Taungs (África del Sur), M. Boule escribía el primer artículo francés sobre el Australopithecus africanus, tomando los datos básicos de un artículo de R. Dart en Nature del 7 de febrero de dicho año y otro con comentarios de paleontólogos ingleses en la misma revista del 14 de febrero. Les añadía importantes comentarios propios y mantenía la información al día ${ }^{12}$.

10 Émile Caftallhac, “A. de Quatrefages”, III, 1892, pp. 1-18, por ejemplo.

10 bis A. PetTit, VI, 1895, pp. 65-69; R. Verneau, VI, 1895, pp. 725-726. En ese mismo volumen, la recensión por $P$. Topinard de un trabajo de Sir William Turner, pp. 605-607.

11 T. XXV, 1914, pp. 595; y XXVI, 1915, pp. 491-492.

12 T. XXXV, 1925, pp. 122-130, 2 figs. y notas en el mismo volumen, pp. 402 y 605-608. 
Gaston Lalanne y el abate Henri Breuil, en 1911, publican el famoso friso esculpido de Cap Blanc (Marquay) y el año siguiente el primero de dichos autores da a conocer los bajorrelieves con representaciones humanas de Laussel (también en la Dordoña). Ambos descubrimientos hicieron cambiar algunas de las ideas que entonces se tenían acerca del arte paleolítico ${ }^{13}$.

Y también muchos artículos y notas sobre la Península Ibérica. Ya en el tomo I se contiene una interesante nota de R. Verneau sobre la Antropología en España y sus museos, crónica que se proseguirá en tomos posteriores. Así, por ejemplo, el volumen correspondiente al año 1898 contiene una amplia "varia» de Luis de Hoyos Sainz titulada "L'Anthropologie et la Préhistoire en Espagne et en Portugal en 1897" 14 . Aqui habría que añadir las docenas de trabajos del abate Breuil y sus colaboradores acerca del arte rupestre en España, tanto el paleolítico como el postpaleolítico, en los volúmenes de los años diez y veinte ${ }^{15}$.

Y si algún día se quiere escribir la historia de los congresos de la especialidad habrá que acudir a las páginas de L'Anthropologie y a sus crónicas. En primer lugar se encontrarán las de la serie del venerable "Congrès d'Anthropologie et d'Archéologie préhistoriques" y luego las de los "Congresos Internacionales de Ciencias Prehistóricas y Protohistóricas" organizados por la "Union Internationales des Sciences Préhistoriques et Protohistoriques" ${ }^{16}$.

Naturalmente la recensión de trabajos importantes publicados en la revista podria alargarse ad libitum, según los intereses de cada lector. Pero, saltando sobre el tiempo, digamos algo de lo que es L'Anthropologie en los años recientes. Con el mismo espíritu de superación científica que inspiró a los "padres fundadores» en los últimos años del siglo XIX, ya a la vista del final del siglo XX. Henry de Lumley, al hacerse cargo de la revista en 1982 , le dió una nueva orientación. Dejando para otros investigadores y organismos la Etnología y la Antropología de las poblaciones actuales (ambas alejadas de la Prehistoria en sus formas modernas), la temática de

13 H. Breull y G. LaLANNE, "L'abri sculpté de Cap Blanc à Laussel (Dordogne)», XXII, 1911 , pp. 385-402, 6 figs.; G. LALANNE; “Bas-reliefs à figuration humaine de l'abri sous roche de Laussel (Dordogne)", XXIII, 1912, pp. 129-149, 7 figs.

14 T. I, 1890. IX, 1898, pp. 37-51.

is Cf. la compilación bibliográfica contenida en E. RIPOLL PERELLO, El Abate Henri Breuil (18771961), Madrid, UNED, 1994 (834 títulos).

${ }_{16}$ Para la serie de la UISPP: crónica del I (Londres, 1932) en t. XLII, 1932, pp. 525-545; análisis de sus Actas, t. XLIV, 1934, p. 585; crónica del II (Oslo, 1936) por R. Vaufrey, en t. XLVII, 1937, pp. 81-98. 
la publicación incluye ahora Prehistoria en sentido arqueológico (con preferencia para el paleolítico), la Paleontología humana, el entorno de hombre fósil, la Geología del Cuaternario y el Arte prehistórico (un fascículo al año). Los más de cincuenta fascículos aparecidos entre 1983 y 1995, con la división tradicional de su contenido, aunque algo simplificada, contienen una extraordinaria cantidad de trabajos de las más variadas geográfias y autores, muchas veces reunidos de forma monográfica ${ }^{17}$.

El programa que se sigue fue expuesto en una nota de $\mathrm{H}$. de Lumley de la que traducimos unas frases:

"La publicación regular de cuatro fascículos anuales seguirá aportando a los investigadores de las ciencias prehistóricas y antropológicas unos textos de gran calidad científica, ofreciendo un amplio panorama de la investigación internacional en su conjunto. De este modo, la colección de los tomos de L'Anthropologie constituirá por si misma en los años venideros, al igual que lo ha sido en el pasado, la gran Enciclopedia internacional de la Prehistoria así como una base de investigación indispensable» ${ }^{18}$.

En efecto, los tomos de L'Anthropologie constituyen una verdadera enciclopedia de la Prehistoria mundial y de la historia de sus avances. Piénsese en todo lo que hay en casi 70.000 páginas de denso contenido. El autor de la presente nota - lector de las páginas de L'Anthropologie desde su juventud en una especie de "vicio" que heredó de su maestro Luis Pericot- siempre ha pensado que algún día habrá que emprender la enorme labor que representa el hacer los índices completos de la revista a la manera como se hizo alguna vez con la Revue Archéologique, su publicación hermana ${ }^{19}$. Hoy en día, con los medios de la informática, la tarea no parece imposible.

En fin, L'Anthropologie cumplió en 1990 sus primeros cien años de existencia, efémerides llena de gloria en la que hay que recordar a los que en el pasado la hicieron posible y llenaron sus páginas de sabiduría y en la que hay que felicitar a los que en nuestros tiempos la han continuado y la

\footnotetext{
17 Paleoantropología de los cinco continentes (t. 87, 1983, fasc. 4; t. 89, 1985, fasc. 1; t. 90, 1986, fasc. 3 ; t. 95, 1991, fasc. 1 y 2.3; Paleolítico antiguo en Europa (t. 92, 1988, fasc. 4); Paleolítico africano (t. 94, 1990, fasc. 2); la Traceologia (t. 93, 1989, fasc. 3); el Arte prehistórico, mueble y parietal (t. 88,1984 , fasc. 4 ; t. 90,1986 , fasc. $1 ;$ t. 92,1988 , fasc. 1 ; t. 93,1990 , fasc. 2 ; t. 94,1990 , fasc. 1). Señalaremos también que uno de los números recientes $(t .98,1994$, fasc. 1) está dedicado a las manifestaciones más antiguas de la Prehistoria americana, con especial atención a la América meridional. Veáse una lista de varios centenares de autores, por países, en $\mathrm{H}$. DE LUMLEY. “Editorial», 97, 1993, pp. 3-8.

18 LUMLEY, "Editorial», citado.

19 Por ejemplo: Y. BEQUignon, Revue Archéologique. Tables des années 1900-1945, Paris, Presses Universitaires de France, 1949, 692 páginas.
} 
han mantenido al día dentro del proyecto fundacional. Con el agradecimiento, además, de los muchos que a lo largo de los años hemos leido con afán sus densas páginas.

\section{EL "INSTITUT DE PALÉONTOLOGIE HUMAINE»}

Una nota de Marcellin Boule en la revista es la primera noticia impresa del I.P.H. En ella se dice: "Con gran júbilo podemos anunciar a los lectores de L'Anthropologie la creación en París de un "Institut de Paléontologie Humaine". Transcribe a continuación el texto de la carta de S.A.S. el Príncipe de Mónaco al Ministro de Instrucción Pública de Francia explicando el proyecto ${ }^{20}$.

En 1911, el propio Boule da la noticia de que el nuevo establecimiento ha sido reconocido de utilidad pública y sus estatutos aprobados (decreto de 15 de diciembre de 1910). De los mismos transcribe un cierto número de aspectos interesantes. También anuncia los nombres de los componentes del primer Consejo de Dirección: Paul Dislève, Salomon Reinach, Marcellin Boule, R. Verneau, Ernest Meyer y Louis Mayer. El Comité de Perfeccionamiento quedaba constituido por los señores Reinach, Boule, Verneau, Cartailhac, Capitan y Villeneuve para Francia el Principado de Mónaco, y por Sir Ray-Lankester y los profesores Von Luschan, Hoernes, Issel y Retzius para el extranjero. El propio Boule quedó designado director técnico al propio tiempo que eran nombrados los dos primeros profesores: el abate $\mathrm{H}$. Breuil para la "Etnografía prehistórica" y el alemán profesor Hugo Obermaier para la "Geología aplicada a la Prehistoria".

En la misma nota Boule anunciaba el que sería el emplazamiento del I.P.H. en el Boulevard Saint-Marcel, en una palacio que construiría el arquitecto Pontremoli ${ }^{21}$. Los trabajos científicos empezaron inmediatamente después de unos "viajes de contactos» efectuados por el abate Breuil (Altamira, Castillo, Hornos de la Peña, Torralba, etc. y hasta la provincia de Almería para ver los yacimientos excavados por Louis Siret) ${ }^{22}$.

$20 \quad$ T. XX, 1910, p. 725.

21 T. XXI, 1911, pp. 111-112

22 Cf. el "Prefacio" del propio H. Breull, en RIPOLL, El Abate Henri Breuil..., citado, en el que relata una parte de sus viajes por España. Louis Siret (1860-1934), ingeniero y arqueólogo belga que pasó casi toda su vida en nuestro pais. Con su hermano Henri, publicó Las primeras edades del metal en el Sudeste de España (Barcelona, 1890). La gran colección que reunió en su casa de Las Rozas, en Herrerías (Cuevas de Almanzora, Almería) la donó al Museo Arqueológico Nacional de Madrid. 


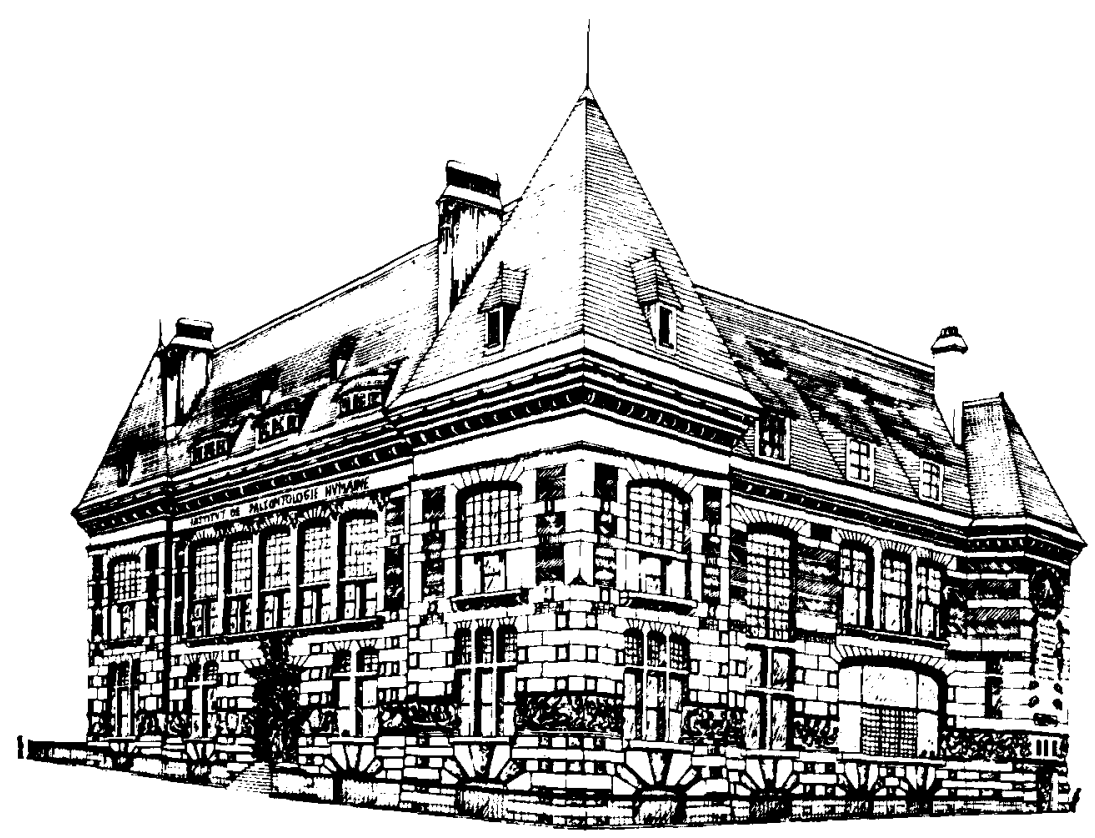

Figura 3. Palacio de Institut de Paléontologie Humaine, Paris. Obra del arquitecto Pontremoli.

¿De donde venía la idea de tan singular institución? ¿Quien fue su generoso mecenas? En respuesta a la primera interrogación hay que poner los nombres de dos lugares. Balzi Rossi y Altamira. Para la segunda hay que consignar un nombre egregio: S.A.S. el príncipe Alberto I de Mónaco.

En el panorama científico europeo de comienzos del siglo XX ocupa por derecho propio un destacado lugar Alberto I de Mónaco (18481922), príncipe soberano y político liberal que, en 1911, concedió su primera Constitución al Principado ${ }^{23}$. Este gran personaje era también un hombre de ciencia. En efecto, el príncipe Alberto -antiguo oficial de la Marina española- era un eminente especialista en ciencias del mar, director de numerosas expediciones en sus yates especialmente preparados y fundador del "Institut Océanographique» de París y del "Musée Océanographique» de Mónaco. También se interesaba por la Prehistoria y la Botánica. Si sus trabajos oceanográficos encerraban

23 Raymond Damien, Albert per., prince souverain de Mónaco, París, Institut de Valois, 1964. 
una preocupación por los orígenes de la vida, en su labor de alentador de los estudios prehistóricos existía un profundo interés por la humanidad primigenia.

Las cavidades de los roquedos de Balzi Rossi o Grimaldi -precisamente el apellido de los soberanos monegascos-, habian proporcionado importantes vestigios paleolíticos ${ }^{24}$. En los años 1882 y 1883 el príncipe trabajó con sus propias manos en la excavación de la Barma Grande, pero no continuó los trabajos reconociendo que la técnica de su equipo no era la adecuada. Doce años después encargó la tarea al canónigo Villeneuve que, secundado por Lorenzi y durante un decenio, realizó excavaciones en las cuevas del Cavillon, Des Enfants y en el grandioso abrigo que luego sería llamado Grotte du Prince. Al estudio de los materiales fueron invitados tres grandes especialistas: M. Boule para la Paleontología, R. Verneau para la Antropología y É. Cartailhac para la Prehistoria. Los hallazgos fueron el punto de partida del futuro "Musée d'Anthropologie Préhistorique" de Mónaco, que ahora sigue siendo la eficiente institución que su fundador proyectó ${ }^{25}$.

Gracias a la decisiva intervención de Gustave Saige, secretario y archivero del príncipe, y de Salomon Reinach (1858-1932) ${ }^{26}$, las carpetas con los pasteles de Altamira hechos por el abate Breuil en 1902 fueron a parar a la mesa de trabajo del príncipe que las examinó entusiasmado. El 11 de noviembre de 1904 se acordó la publicación del gran volumen sobre Altamira ${ }^{27}$ y se formó un trust para la ulterior publicación de las cuevas con arte que se iban descubriendo, con los franceses É. Cartailhac, $H$. Breuil, F. Daleau y Denis Peyrony y los españoles Hermilio Alcalde del Río y Juan Cabré Aguiló. Nació entonces la relación directa entre el abate Breuil y el príncipe Alberto que le encargó la realización de excavaciones en cuevas santanderinas y con equipos internacionales (El Castillo, Hornos de la Peña, El Valle y otras). El abate le pidió que para estos trabajos se pudiera contar con la colaboración de sus amigos Hugo Obermaier (1877-

24 Entre 1870 y 1875, ÉMILE RIVIERE (1835-1922) realizó en dichas Cuevas el descubrimiento de seis esqueletos humanos de edad paleolítica, lo que dió lugar a una polémica con Gabriel de Mortillet.

25 I. de Villeneuve, M. Boule, R. Verneau y É Cartallhac, Les grottes de Grimaldi, Mónaco, 1906 y 1919 (2 vols.).

26 Arqueólogo, filólogo, epigrafista e historiador del arte y de las religiones, autor de abundante bibliografía, fue durante muchos años codirector de la Revue Archéologique. Interesado por el arte prehistórico, publicó en 1913 su Répertoire de l'art quaternaire, que cataloga el arte mueble y parietal conocido hasta 1912.

27 Emile Cartailhac y Henfi Breuil, La caverne d'Altamira à Santillane, près de Santander (Espagne), Mónaco, Imprimerie de Mónaco, 1906, VIII L 287 pp. 205 figs. y 38 láminas. 
$1946)^{28}$ y H. Alcalde del Río (1866-1947) ${ }^{29}$. El príncipe Alberto visitó las principales cuevas cantábricas en 1909. Probablemente la idea de fundar el I.P.H. nació durante este viaje y los comentarios acerca del mismo con $\mathrm{M}$. Boule. Breuil narró así la primera noticia que tuvo del proyecto:

«El 13 de octubre de 1909 un telegrama me pedia que me trasladara al castillo de Marchais, cerca de Laon. Después de comer, el príncipe, en traje de caza, con su arma, me llevó a los bosques. Nos sentamos al borde de una turbera, me explicó entonces su intención de fundar, bajo la dirección del profesor Boule, un Institut de Paléontologie Humaine en el que Obermaier y yo podríamos proseguir nuestras investigaciones. Me encargó que elaborase para él, con el señor Boule, que era quien había tenido la primera idea, un proyecto detallado que le llevé el 21 de diciembre siguiente a Marchais" ${ }^{30}$.

Las gestiones prosiguieron y finalmente y de forma definitiva las cátedras establecidas fueron las siguientes: $M$. Boule la Paleontología; $R$. Verneau la de Antropología; $\mathrm{H}$. Breuil la de Etnografía prehistórica; y $\mathrm{H}$. Obermaier la de Geología del Cuaternario.

Estaba previsto que el palacio que tenía que albergar el I.P.H., bello edificio en la calle Rene Panhard, no lejos del "Museum", sería inaugurado a finales de 1914, momento en que el edificio estaría acabado y amueblado. Pero la guerra y la postguerra inmediata impidieron la inauguración.

28 Sacerdote, prehistoriador y geólogo alemán. Director con el abate Breuil de las excavaciones de la Cueva del Castillo (Puente Viesgo) (1909-1914) y descubridor con Paul Wernert y $\mathrm{H}$. Alcalde del Río de la Cueva de La Pasiega en el mismo lugar. Durante la guerra de 1914-1918 se quedó en España, luego se naturalizó español y fue el primer titular de la cátedra de Historia Primitiva del Hombre de la Universidad de Madrid (1922). Su obra más notable es El hombre fósil (Madrid, 1916; ed. ampliada en 1925 que fue traducida al inglés y al alemán y ha sido recientemente reeditada - Madrid, Istmo, 1985-, con notas de J.M. Gomez-TABANERA, H.-G. BANDI, G. López Junguera Y E. Aguirre. De su libro El hombre prehistórico y los orígenes de la Humanidad (Madrid, Revista de Occidente, 1932) se hicieron siete ediciones. Necrología por H. BREUIL, en Bulletin de la Société Préhistorique Française, XLIII, 1946, pp. 287-288.

29 Autor de grandes descubrimientos de cuevas con arte en la región cantábrica: El Castillo, Hornos de la Peña y Covalanas, en 1903; Santián, en 1905; La Clotilde de Santa Isabel, en 1906; El Pendo y La Meaza, en 1907; El Pindal, Mazaculos, Quintana y La Loja, en 1908; Las Aguas, en 1909; y Atapuerca (Burgos) en 1910 (algunos con el padre Lorenzo Sierra y otros con el abate Breuil). Autor de Las Pinturas y grabados de las cavernas prehistóricas de la provincia de Santander, Santander, Blanchard y Arce, 1906 (también en la revista Portugalia del mismo año). La mayoría de aquellos hallazgos en: H. BreUIL, H. ALCALDE del RIo y L. Sierra, Les cavernes de la région cantabrique, Mónaco, Imprimerie Vve. A. Chene, 1911, VIII, 265 pp. 258 figs. y 100 lá. minas. Benito Madariaga de la Campa, Hermilio Alcalde del Rio, una escuela de Prehistoria en Santander, Santander, Patronato de las Cuevas, 1972. E. Ripoll Perello, “Algunas cartas de don Hermilio Alcalde del Rio al Abate Henri Breuil", Homenaje al Dr. Joaquin Gonzalez Echegaray, Santander, Museo de Altamira, 1994, págs. 199-204.

${ }^{30}$ H. BreulL, "Souvenir sur le Prince Albert de Monaco et son oeuvre préhistorique", Bulletin de la Société Préhistorique Fran çaise, XLVIII, 1951, pp. 287-288. 
Finalmente, de forma solemne, el I.P.H. fue oficialmente abierto e inaugurado el 23 de diciembre de 1920, con la asistencia del príncipe Alberto y del presidente de la República Francesa, Alexandre Millerand, acompañados de numerosas personalidades. El príncipe pronunció un discurso sobre la Paleontología y la evolución humana. Entre otros, habló también E. Cartailhac que subrayó el encadenamiento de la actividad del nuevo centro con la de los pioneros de la Prehistoria, por ejemplo con la de su maestro Edouard Lartet, el cincuentenario de cuya muerte se cumplía precisamente este mismo día. Para señalar el ambiente traduciremos unas frases del discurso del príncipe:

«De este modo, mientras que las ciencias consagradas al estudio físico y paleontológico de nuestro planeta buscan una base para fijar, a los seres que nos ocupan, una edad ante la que toda estimación se hace imposible en el momento presente, pero que se encara fácilmente con un mínimo de una cuarentena de milenios, he aquí que nos encontramos entre los testimonios de esos lejanos tiempos, en las cavernas de España y de la Francia meridional, ciertas pinturas correctamente dibujadas por un Hombre prehistórico muy primitivo conforme a los utensilios que dejó y los animales que fueron sus contemporáneos. Ya ese hombre era capaz de sentir una emoción artística y expresar su atractivo mediante la obra de sus manos y el análisis de sus ojos. En ese mundo, dos formas de la actividad humana apenas marcadas por unos rasgos avanzan cogidas por la mano. Es la revelación de un sentimiento" ${ }^{31}$.

A pesar de la generosidad del príncipe, la nueva institución se encontró pronto con dificultades financieras que se acentuaron al morir el mecenas en 1922. Por ello no tuvo en algunos momentos la brillantez de vida con que había sido concebido. Aunque se inició una importante colección de memorias - los Archives de l'Institut de Paléontologie Humaine-, la serie de las grandes publicaciones sobre arte prehistórico no fue continuada después de la monografía dedicada a Les Combarelles en $1924^{32}$. Con todo, el I.P.H., gracias a su profesorado, a L'Anthropologie y a sus instalaciones, siguió cumpliendo su misión como centro de alta investigación y de perfeccionamiento - centenares de jovenes investigadores franceses y de otras nacionalidades pasaron por sus salas y su biblioteca al correr de los años-. Esta acción se prosiguió en los años posteriores, incluidos los aciagos de la Segunda Guerra Mundial ${ }^{33}$.

\footnotetext{
32 L. Capitan, H. Breuil y D. Peyrony, Les Combarelles aux Eyzies, París, Masson, 1924, X 192 p., 128 figs. y 582 láminas.

${ }_{33}$ Hemos seguido el cap. 6, "Alberto I de Mónaco y el Institut de Paléontologie Humaine", el libro de RIPOLL, El Abate Henri Breuil..., citado.
} 561-573.

31 “Inauguration de l'Institut de Paléontologie Humaine", L'Anthropologie, XXX, 1920, pp. 
Ahora, el I.P.H., con su edificio bien restaurado, bajo el patrocinio compartido del Principado monegasco y del Estado francés, sigue siendo un centro abierto a todos los prehistoriadores y del que parten empresas científicas en las que colaboran organismos afines de todo el mundo. Tras la larga y marcada huella del profesor M. Boule, han sido directores del I.P.H. los profesores $\mathrm{H}$. V. Vallois, Lionel Balout y Henry de Lumley, este último actualmente en funciones. Gracias especialmente a los profesores Vallois y De Lumley, el I.P.H. se ha mantenido durante muchos años en estrecha relación con el "Musee de l'Homme" (sucesor en 1937 del antiguo "Musée d'Ethnographie" del Trocadero). Este gran centro de la investigación y de la exhibición de la Prehistoria y la Etnología, se encuentra ahora con la amenaza de ser convertido en un museo de Arte, asunto del que seguramente se oirá hablar. Pero esta, como decía Kipling, "es otra historia». 